\title{
Psychosomatic aspects of hypertension
}

\author{
BERNARD HEINE \\ M.B., D.P.M. \\ Lecturer, Department of Psychiatry, St. George's Hospital, London, S.W.17
}

THE relationship between emotions and blood pressure has fascinated writers for centuries. The interest is in no way lessened by the fact that, whereas level of blood pressure is raised temporarily by emotional states, there is little evidence that these, when prolonged, lead to hypertension. But the belief remains that a causal connection should exist and this is reflected by the persistence of relevant research.

The search for a major and specific cause for essential hypertension has been unsuccessful. Approaches have varied from examining genetic factors, neural mechanisms, humoral factors including disturbed renal function to more complex ones at a cerebral level. In addition, the effects of age, sex and obesity have been better defined and the social characteristics of hypertensives examined. All these studies reveal small pieces of a jig-saw, so piecemeal it is difficult to see their relationship even at a hypothetical level. It leads, therefore, to the conclusion that the cause of raised blood pressure is multifactorial. In a clinical setting the relationship between psychological factors and blood pressure must be seen in this perspective. Firstly, from the point of view of genesis, mental factors may contribute to hypertension along with others and, secondly, in the assessment and management of essential hypertension the emotional state of the patient is clearly important. While this is recognized by clinicians in the individual patient, this aspect and the dealing with emotional problems is rarely presented as a part of systematic treatment. Very likely, this is due to the uncertainty surrounding the significance of mental factors or the apparent remoteness of work by the experimentalists.

In any study of blood pressure certain problems recur which go some way to explain the lack of uniformity in results. Common difficulties are those of definition and criteria of methods used, technique of measurement, the selection of subjects or a population and the influence to which they are exposed. Any enquiries into the relationship between psychological variabilities and blood pressure are doubly difficult, for the former presents equal, if not more, complex problems in measurement.
Acute emotional stress and blood pressure response

A large literature exists on the relationship between acute emotional states and blood pressure changes. Overall, there is agreement that stimuli of various kinds raise blood pressure temporarily (Martin, 1960). A new situation, an examination, mental test or a threat are common examples, all of which are assumed to provoke emotion. The precise nature of this feeling is often difficult to define. Cannon (1932) first suggested that emotion was a generic term and acted as a general stimulus, producing an emergency pattern of physiological changes. But other work (Ax, 1953; Schachter, 1957) suggests a distinction should be made between fear or anxiety and anger, the former only producing a consistent increase in blood pressure and heart rate. A current approach, which avoids this problem to some extent, is to see the vascular response to a stimulus as part of the orienting reflex (Pickering, 1968). But common to most studies is the finding that the response is transient. This remains true despite the same stimulus producing different responses in different individuals and ones which may remain stable for years (Lacey \& Lacey, 1962). The degree of vascular response is affected by other factors; it is prolonged or exaggerated in neurotic patients (Malmo, Shagass \& Heslam, 1951), in those thought to have a genetic predisposition to hypertension (Doyle \& Fraser, 1961) and in those who already have a raised blood pressure (Wolf \& Wolff, 1951; Smirk, 1957).

\section{Emotional stress and physiological disturbance}

The haemodynamic changes that occur in response to acute stress vary. Usually, in normotensives and young hypertensives cardiac output only increases but Brod (1970) has shown that if the stimulus is a cold pressor test and not a mental one cardiac output may fall and the rise in pressure be due to an increase in total peripheral resistance. Associated changes have been demonstrated in pressor-amine metabolism. For example, Nestel (1969) showed that labile hypertensives, when subjected to a mental task, had 
significantly greater changes in blood-pressure and adrenaline and noradrenaline excretion than matched controls. Endocrine and lipid metabolism have been examined by Carlson, Levi \& Orö (1968) who found an association between emotional states of anger or arousal and raised blood pressure, catecholamine excretion and plasma free fatty acids. Other workers have shown an increase in 17-hydroxycorticosteroids (Charvat, Dell \& Folkow, 1964). One might conclude that such responses, when repeated enough, could lead to sustained hypertension. But most evidence suggests that catecholamine excretion is not increased in essential hypertension (Brunjes, 1964) and that this mechanism is not important in its genesis.

A quite new approach has been to demonstrate that autonomic responses, both glandular and visceral, can be instrumentally learned. Miller (1969) has been responsible for the bulk of this work and for the view that psychosomatic symptoms associated with the autonomic system may be the result of learning experiences. It is a short step to postulate critical periods in early development when such maladaptive responses could be learned and perpetuated. More specifically, Dicara \& Miller (1968) were able to show in curarized rats that changes in systolic pressure when reinforced were able to be learned. Similar responses have been achieved in human subjects (Shapiro, Tursky \& Schwartz, 1970); heart rate and systolic blood pressure could be altered by operant conditioning methods and each independently of the other. Although such changes were not great, this finding could be of value therapeutically. Again, animal studies have provided a model for examining the effect of stimulating cerebral areas. A wide variety of visceral changes including some within the circulation, occur when different areas of the brain are stimulated (Magoun, 1963). Interest has focused on the hypothalamus where stimulus of the lateral area produces the so-called defence alarm reaction. If these stimuli are repeated for weeks a sustained hypertension develops (Folkow \& Rubinstein, 1966).

\section{Prolonged emotional stress and blood pressure response}

The work already cited is of great theoretical importance in the understanding of possible mechanisms (of which there is a wealth) but the evidence for this occurring in man in essential hypertension is regrettably flimsy. Stress cannot be applied experimentally to a human subject for a lengthy period in an attempt to produce pathological and irreversible changes and in man we are practically confined to war, natural disasters or environmental stimuli (such as noise) assumed to be 'harmful'.
A different approach is to select subjects who are clearly emotionally disturbed due to overt menta illness and to observe blood pressure changes sub- $\frac{\mathrm{c}}{\mathrm{c}}$ sequent to lengthy or repeated episodes. This avoids the problem of defining an external stimulus but raises? others such as criteria of recovery or length ofo follow-up. First, it requires to be shown that mentato illness itself is currently associated with a raised pres $\overline{\bar{n}}$. sure. There is some uniformity in the literature de $-\mathbb{Q}$ spite varying methodology. Alexander (1902) waso one of the first to note that patients admitted to as mental hospital had higher pressures compared with $\vec{\circ}$ the general population, and Parkin (1927) showed $\overrightarrow{\vec{\omega}}$ that the admission blood pressure of patientso $(140 / 95 \mathrm{~mm})$ fell on recovery $(120 / 83 \mathrm{mmHg})$. The study by Paddle (1928), a model for its sound method 3 . is more detailed; he found a steady rise in pressures with age, no difference in depressed and manicr states and overall a higher pressure than would be expected for a particular decade. An early report byer Bruce \& Alexander (1900) describes findings similar to the later studies but has the additional conclusion? that the restoration of normal sleep appeared tolower systolic pressure. From the diagnostic aspect there is some agreement (Hall, 1927; Altschule, 1953) that neurotic illness is not associated with sustained? raised levels of blood pressure. But depressive illngss and, in particular, involutional depression has ben found to be related to raised levels of blood pressu when the patient is ill. In a comprehensive review? the subject, Altschule (1953) cites some twenty-one references in support of this view.

Secondly, it needs to be demonstrated that re $\frac{0}{0}$ peated depressive illness leads to a sustained hypertension, an enquiry beset with methodological prob- $\overrightarrow{\overrightarrow{0}}$ lems and reflected in the paucity of such studies. In a group of forty patients who had previously suffered from depressive illnesses and who were. followed up for a mean period of 10 months after? discharge from out-patients, Heine (1970) showed $a$ significant correlation between the number of spells of illness and recovered blood pressure. This finding was confined largely to women patients but could not be accounted for by age, weight or differing forms of treatment. Further, blood pressure on recovery was significantly higher than in a control group. Theres was no evidence that raised blood pressure itself pre disposed to depression. In an earlier study with twenty-five patients (Heine, Sainsbury \& Chyno N weth, 1969), the characteristics of the illness werm found to be important; blood pressure when ill was correlated with anxiety and agitation characterizing the depression and these clinical features also deter? mined whether the pressure fell with recovery. The relevance of such findings to the genesis of hyperten:sion may appear tenuous but the selection of ans extreme emotional state for consideration of its long 
term effect on blood pressure can provide a useful model. Moreover, depressive illness is accompanied by neurohormonal changes and electrolyte disturbances within the body and anxiety by changes in central neurophysiological function. Lader \& Wing (1969) demonstrated a difference in arousal measures in predominantly agitated depressives compared with predominantly retarded ones: the former showed a significantly higher mean skin conductance and more spontaneous skin fluctuations. A further step would be to relate such different physiological patterns to blood pressure change.

Studies on the effect of severe or prolonged external stimuli on a population have been limited by their short periods of follow-up. Ruskin, Beard \& Schaffer (1948) describe the response of a population in Texas to a natural disaster, a vast explosion. An elevated diastolic pressure $(>95 \mathrm{mmHg}$ ) was present in $56 \%$ of the survivors $1-2$ weeks after the event; surgical patients were used as controls of which only $34 \%$ showed similarly elevated pressures prior to the explosion. The classic paper describing observations in war time is that of Graham (1945). He examined 695 soldiers, aged 20-28 years, who had spent at least a year in desert warfare and measured their blood pressures 4-8 weeks after retiring to a noncombat area. Pressures recorded were unexpectedly high: the mean for the whole group was 154/99 $\mathrm{mmHg}$ and 187 of the subjects had diastolic pressures exceeding $100 \mathrm{mmHg}$.

Because of the limitations of human studies, one must briefly return to animal work. It has been shown that both rats (Farris, Yeakel \& Medoff, 1945) and mice (Henry, Meehan \& Stephens, 1967) develop long-term raised pressure when subjected to lengthy stresses. Russian workers (Simonson \& Brozek, 1959) have applied Pavlovian conditioning techniques to produce similar results but these have not always been replicated in the west (Shapiro \& Horn, 1955). A quite different approach has been to study the importance of the effect of drugs and diet in pregnancy (Grollman \& Grollman, 1962): a year after birth 'treated' cats had blood pressures 25 $\mathrm{mmHg}$ higher than in controls. It is difficult to envisage comparable studies in man.

\section{Socio-cultural factors and blood pressure}

To return to man, it is an appropriate time to consider socio-cultural studies (see Scotch \& Geiger (1963) for a comprehensive and penetrating review). In the main, these are cross-sectional studies of a defined group in which blood pressure levels are related to various social characteristics.

The relationship of blood pressure to occupation has yielded varied results. Miall \& Oldham (1958) examined two communities in Wales and showed an association of higher pressures with higher standards of living and light occupations with less energy expenditure. The authors are careful not to point a causal connection. A study by Morrison \& Morris (1959) showed that London bus-drivers had higher blood pressures than conductors; it could be concluded that nervous strain in the former occupation may lead to a raised pressure. But Newnham (1952) in a study of two groups of elderly British Railway workers, distinguished by whether they did heavy or light work, found no difference in mean pressures between them.

In contrast, work in the United States (Berkson et al., 1960; Stamler et al., 1960) has usually not demonstrated a relationship between cardiovascular disease and socio-economic strata. (But note racial differences, Lennard \& Glock, 1957.)

These diverse findings underline the limits of using such a variable: occupation can be viewed as the result of both current social and highly personal factors. Findings are more uniform as to family size. Both Bøe, Humerfelt \& Wedervang (1957) and Miall \& Oldham (1958) found that larger families are associated with lower parental blood pressure.

Cross-cultural studies have attempted to demonstrate that groups with high blood pressures have increased social tension or conflicts. An example is the well-planned and detailed study by Scotch (1963) contrasting a rural and urban Zulu population. The latter had higher mean blood pressure and greater frequency of hypertension for all age groups and both sexes and it was hypothesized that 'stress' was more frequent and more severe in the citydwellers. Scotch emphasizes the unsatisfactory nature of this term which may well obscure more specific variables of a social kind. On comparing hypertensives with nonhypertensives in the urban community, the essential finding was that the former could not adapt to the demands of urban life.

In an elegant study, using distribution curves, Cruz-Coke (1960) examined blood pressures in two sub-samples of a homogeneous population (policemen) in Peru. Both had been born in similar conditions but one group had emigrated to a "western civilization' city some years prior to the other. The mean diastolic pressure of the former was 76.8 $\mathrm{mmHg}$ compared to $65.1 \mathrm{mmHg}$ of the very recent arrivals.

To summarize, then, there is some evidence that raised blood pressure is associated with difficulty in adjusting to the demands of a complex and civilized existence. Certainly, the social setting appears important but to identify the relevant factors more precisely requires, in addition, measures of the individual's perception and interpretation of his environment. 
Personality characteristics and blood pressure

Although this area has been a fruitful one for research, especially in the United States, the harvest is somewhat mixed. Basically, there are two approaches: a study of personality traits in patients who already have an established hypertension (when conclusions are limited by the disease itself affecting behaviour) or classifying a 'normal' population by blood pressure level and comparing the groups for personality characteristics. Many of the studies present faults in their methodology, in particular highly selected populations and possible observer bias (Glock \& Lennard, 1957). Yet there is some consistency in the interpretation of reported findings. The theme common to many is that people with raised blood pressure experience a conflict between passive, dependent longings and aggressive, competitive impulses and, further, a conflict between anger and hostility and the need to repress these for fear of losing love or esteem (Alexander, 1939; Ostfeld \& Shekelle, 1967). For example, Saul (1939) regarded hostility and difficulty in expressing anger as characteristic of hypertensives and Saslow et al. (1950) identified subnormal assertiveness and obsessive compulsive behaviour as traits associated with hypertension.

Harris et al. (1953), using several forms of psychological assessment, compared two groups of college women. 'Normals' had pressures of $120 / 80 \mathrm{mmHg}$ or less and 'prehypertensives' of at least one reading above $140 \mathrm{mmHg}$ systolic or $90 \mathrm{mmHg}$ diastolic. Observers rating the subjects applied 'negative' adjectives to describe the 'prehypertensives' and it is suggested they are less able than 'normals' to handle frustrating situations, a reaction linked to blood pressure rise.

Some 4 years later, Sokolow et al. (1961) examined the same cohorts applying similar techniques. The 'prehypertensives' again had higher pressures than the normals and further, were said to be more assertive and hostile and show conflict over sexual identification. Scotch \& Geiger (1963) very rightly point out two limitations of these studies: the $50 \%$ drop-out of subjects at follow-up and that traits perceived in 'normals' could be interpreted in precisely the same way as those in the 'prehypertensives'. A further question is the validity of using labile hypertension to imply subsequent development of hypertensive disease.

It is a pleasure to cite the work of Ostfeld (see Ostfeld \& Shekelle, 1967, for a succinct review of psychological factors in hypertension): his writing is a model of clarity, his views stimulating and his research carefully planned. With Lebovits (Ostfeld \& Lebovits, 1959) he examined personality traits, as measured by the Minnesota Multiphasic Personality Inventory (MMPI) and Rorschach test, in three groups: essential hypertensives, renal hypertensivesڤ and normal controls. The results showed no differ- 3 ence in scores between the three groups. Findings $\mathbb{\complement}$ were similar on a group of Western Electric workers, $C$ that is, a 'normal' population. A high and low blood $\overrightarrow{\vec{c}}$ pressure group were identified, matched for age and $\stackrel{5}{?}$ arm girth, with seventy-seven subjects in each. 듬 Mean scores on the MMPI and the Cattell $16 \frac{\bar{c}}{\bar{\omega}}$ Personality Factor Questionnaire were well matched $\vec{\Phi}$ between the two. An extension of the enquiry was to $\Omega$ take workers with a positive family history of hyper-ळ tension and divide them into high and low blood $\vec{\circ}$ pressure groups. Again, scores of the personality measures did not differentiate them in any way. $\vec{\rho}$ Thus, in subjects predisposed to raised blood pres $\frac{\sigma}{0}$ sure genetically, personality traits appear not to $\frac{6}{3}$ play an important part in its causation. But impressive as these studies are, there is the obvious limita-. tion imposed by the questionnaires used and their ability to assess functioning of personality in any ${ }_{i}$ depth.

An important prospective study has now con-음 tinued for some 20 years (Thomas, 1965). The sub- jects are Johns Hopkins medical students, in whom blood pressure, personality factors and genetico history are assessed at their training stage. Thejir क्? subsequent health and morbidity are followed wit in addition, an attempt to assess stresses encountere्g $\mathrm{d} \cup$ during life. Little of significance has so far emerged.but could be expected to shortly.

The investigations of Wolff and his associates into essential hypertension have continued for manyo years and, with time, have changed in emphasis. In an early study (Wolf et al., 1948), these workers $\AA^{\circledR}$ demonstrated very clearly that introduction of topics $\overrightarrow{\overrightarrow{0}}$ arousing feelings of conflict caused a sharp rise in 3 systolic and diastolic pressure in hypertensives. This response was accompanied by a decrease in renal blood flow. But in some hypertensives, chargedo topics produced a fall in pressure, emphasizing how specific to an individual the vascular response is.

Later work (Christensen \& Hinkle, 1960) compared managers in an American corporation from two different backgrounds. One group was made up of high school graduates who had risen to theiro present post through the ranks (taken to imply they were living in a social environment which was unfamiliar and threatening) and the other of recently N appointed college graduates (implying a more affluent and stable background). The former group $N$ had significantly more new illnesses during the periodw of observation and more persistent pressor responses, But when hypertensive members were identified and을 compared with the other members of their own group on some seventy items covering background, pre-? vious experiences and current state, they did not $\frac{0}{0}$ differ. 
These findings must be seen in the context of Hinkle \& Wolff's (1961) broad view of illness. Their thesis, derived from consistent results in a variety of selected populations, is that distribution of illness is significantly skewed by the high illness experience of a minority and that these vulnerable people perceive life as demanding, threatening and frustrating. Hypertension is seen as just one possible mode of response. We are thus still left with the basic question: what determines an increased and sustained vascular response in an individual?

A classic paper which stands apart for its different approach is that of Miller (1939). He assessed repressed aggression by clinical interview in paranoid and depressed patients and predicted that those who showed this most markedly would have higher pressures. His subjects were graded into three categories of repressed aggression and he was able to demonstrate parallel levels of blood pressure (means of $157 / 100 \mathrm{mmHg} ; 141 / 93 \mathrm{mmHg} ; 110 / 78$ $\mathrm{mmHg}$ ) in support of his hypothesis.

Compared with America, the approach in this country has been more circumscribed. It has concentrated mainly on measuring neuroticism by the use of the Eysenck Personality Inventory (Eysenck \& Eysenck, 1964), the initial postulate being that neuroticism would be associated with raised blood pressure. Sainsbury (1960) first published his findings that hypertensive out-patients had significantly higher neurotic scores than control patients but Robinson (1962) in a study on an unselected group of subjects was unable to demonstrate any such relationship. A likely explanation of these diverse findings was the unrepresentative nature of Sainsbury's patients. Recent work suggests the pendulum has swung in the opposite direction. A carefully executed study by Davies (1970) of a group of male factory workers demonstrates a negative correlation between neuroticism scores and level of blood pressure. This is in line with psychosomatic theory (Wolff, 1953) that a psychosomatic disease such as hypertension arises in individuals who are unable to express their conflict and feelings in neurotic symptoms. At the Prague Symposium in 1960 there was some consensus of opinion amongst several speakers. Hinkle \& Wolff (1961) reported that hypertensive members of a population were, if anything, less complaining than the other members; Sokolov et al. (1961) note that in prehypertensives anxiety was less bound to neurotic symptoms and, from Russia, Miasnikov (1961) states that very often patients with essential hypertension completely deny nervous symptoms. He suggests that in fact hypertensives are people who, although inclined to increased emotion, suppress these reactions.

A recent report (Medalie et al., 1970) from Israel has an interesting theoretical implication. This is, that in addition to disease arising as a result of stresses and an individual's inability to deal with frustration or express conflicts, the disease response is specific to the individual. This paper reports on an adult male population and demonstrates an inverse and significant association between the incidence of essential hypertension and peptic ulcer for the age group 40-49 years.

The concept of 'field dependence' and its relation to psychosomatic illness is a new and interesting one. The meaning of this term needs to be clarified but suggestibility is said to be characteristic of the field-dependent (Linton \& Graham, 1959). Patients with peptic ulcer (Gordon, 1953) and bronchial asthma (Fishbein, 1963) are more field-dependent than normal controls. Silverstone \& Kissin (1968) tested the hypothesis that hypertensives would be less field-dependent than peptic ulcer patients and that normal controls would fall between the two. This notion stemmed from observations that ulcer patients were mainly passive-dependent (Brown et al., 1956) and hypertensives obsessive-compulsive (Gressel et al., 1949). But it needs to be recalled that hypertensives are also claimed to have difficulties with passivity and dependency. However, the results of their enquiry supported the hypothesis: scores of field-dependence were significantly higher in ulcer patients compared with hypertensives and mean values for controls lay between the two. While obvious questions arise as to the implications of this concept and the findings, they merit attention as a new approach to personality function.

\section{Psychological factors and essential hypertension}

It would be gratifying to be able to draw together the threads of the previous sections and apply them with some coherence to the clinical management of hypertensive disease. Alas, it is not possible. Much of the work already cited, though of considerable interest, is too tentative or diverse to be of value in a treatment setting.

One relevant question is whether psychological events are important in precipitating hypertension. Methodology in such an enquiry is crucial: a control group is essential, and the assessment of events complex. Further, although mental factors may be important in bringing the patient to the doctor, a raised blood pressure may have preceded this step by years. Again, hypertension itself may alter a patient's perception of his environment. (Hence an assessment of external stress would need to be confined to relatively hard data.) Not surprisingly, the results from such enquiries are conflicting. Reiser $e t$ al. (1950) studied 230 patients with hypertension, emphasizing psychiatric aspects, and found the majority had experienced psychological stresses prior 
to the onset of symptoms. But in other work (Weiss et al., 1952) no evidence was found to support such a view.

A clearer picture emerges as to the neurotic characteristics of hypertensive patients. We have seen that whereas Sainsbury (1960) showed hypertensive outpatients were more neurotic than other groups, Robinson (1969) in a study on a general population could find no such relationship. This raises the matter of selection of patients. Cochrane (1969) showed that patients attending their general practitioners were more neurotic than the rest of the population and that within this group a high neurotic score was not associated with a raised blood pressure. Although there is no evidence that moderate hypertension is linked with symptoms of headache, Robinson (1969) found that complaints of headache prompted a general practitioner to measure a patient's blood pressure; but no particular symptoms were related to a raised blood pressure. In a study of a normal population, subjects with raised blood pressures complained of no more headaches than those with normal levels (Waters, 1971). These observations, highlighting selection by patients themselves and by general practitioners, need to be recognized by physicians. Patients referred to them may have a high neurotic score and this may lead to an exaggerated blood pressure response to the interview. Besides being relevant to assessment of patients, these factors also apply to any evaluation of drug therapy of raised blood pressure. Clinic patients may well be unrepresentative of the general population with a bias to neurotic patients, who respond well to regular supervision and support.

The place of psychological treatment in the clinical management of hypertensive patients receives scant attention in most text-books. This is understandable as dealing with a patient's emotional difficulties may lower the blood pressure by a few $\mathrm{mmHg}$ only (though improve the patient's mental state) whereas the effect of anti-hypertensive drugs is dramatic, that is, on blood pressure level. There is the problem, too, of deciding whether mental symptoms are the result of raised blood pressure or preceded its onset. Smirk (1957), who is very aware of the importance of mental factors in relation to blood pressure, takes the view that there is ample clinical evidence that discussing hypertensive patients' emotional problems improves their clinical state. Conversely, he describes several patients whose mental state was greatly improved (with lessening of tension, aggression and irritability) by reduction of blood pressure with drugs. But it is also evident that Smirk's clinic was a supportive and friendly one which in itself would have some therapeutic impact. There is no firm evidence that raised blood pressure per se predisposes to overt psychiatric illness. A different matter is the depressive effect of rauwiloid drugs used in treatment (Locket, 1955).

In general, attempts to reduce blood pressure in尺 hypertensives by specific forms of psychologicaftreatment have been disappointing. In a series of $114 \overrightarrow{{ }_{5}}$ hypertensive patients treated with psychotherapeutic interviews for varying periods, Wolf et al. (1955)ह found blood pressure returned to normal levels inō fourteen. Half of these were re-examined 10 yearso later and only one was normotensive. The use of psychoanalytic techniques has yielded no better ${ }^{\text {s }}$ results (Moses, Daniels \& Nickerson, 1960). Thuse there is no evidence that such therapy alters the course of hypertensive disease markedly if at all. But in individual cases there are reports of effective lower:ing of blood pressure (Hambling, 1952; Groen, 3 Van der Valk \& Bastiaans, 1957) and the need is to identify such patients clinically. When prefrontal $\mathrm{C}_{\mathrm{r}}$ leucotomy is performed on patients with severes mental illness, those with hypertension usually showo a lowering of pressure (Groen, 1951) but, in most $\nexists$ this is only a temporary effect (Chapman et al., 1950). 을

Currently, then, the place of psychological treat-ment in the management of essential hypertension is $D$ seen as additional to more specific measures. It willo contribute most to the patients' sense of well-bei的产 rather than to a striking fall in pressure.

A review such as this may appear excessividy critical. Comment has already been made on the methodological difficulties inherent in measuriqgo blood pressure or assessing psychological factors. Consequently most studies are unable to fulfil allo the criteria expected of a scientific enquiry. Although results are often incomplete or at variance with other을 work, they point to further research and provide some $\overrightarrow{\overrightarrow{0}}$ basis for speculation. It may be of value to select 3 some of the more promising aspects of the work? reviewed.

The possible link between a transient blood pres-음 sure rise in response to stress and sustained hyper $\underline{3}$. tension remains as uncertain as ever. This is true $\frac{\sigma}{3}$ despite the large number of mechanisms which have been examined and appear to play a part in short- $\frac{O}{3}$ term blood pressure change. One of the most attractive areas derives from Miller's (1969) work on con-은 ditioning with the notion that such a pattern of $\frac{D}{8}$ response may be set up at critical periods of development. This would seem a rewarding area to explore. N Work on human subjects is clearly limited in scope and animal models will need to be used. Personality factors are far from being exhausted. More emphasis $\omega$ on the individual's personal interaction with his environment, assessed in greater depth, would seem a fruitful area to explore. But the obvious problem is that of new, more specific and yet satisfactory methods of personality assessment. Further, if sig- $\frac{0}{0}$

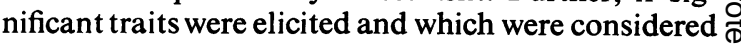


maladaptive, the next step is to test whether they can be altered. At present, psychological methods have a limited application to the management of essential hypertension. It would appear worthwhile examining again the effects of psychotherapy but in hypertensive patients selected for prominent emotional difficulties or personality problems. Finally, to return to the operant conditioning work, this would appear to provide another approach to see if a pressor response can be altered.

\section{References}

AlexANDER, F. (1939) Emotional factors in essential hypertension. Psychosomatic Medicine, 1, 173.

AleXANDER, H. (1902) A few observations on the blood pressure in mental diseases. Lancet, ii, 18.

Altschule, M.D. (1953) In: Bodily Physiology in Mental and Emotional Disorders, pp. 14-22. Grune \& Stratton, New York.

Ax, A.F. (1953) The physiological differentiation between fear and anger in humans. Psychosomatic Medicine, 15, 433.

Berkson, D.M., Stamler, J., Lindberg, H.A., Miller, W., Mathies, H, Lasky, H. \& Hall, Y. (1960) Socioeconomic correlates of atherosclerotic and hypertensive heart disease. Annals of the New York Academy of Sciences, 84, 835.

Bøe, J., Humerfelt, S. \& Wedervang, F. (1957). The blood pressure in a population. Acta medica Scandinavica, 157, Suppl. 321.

BROD, J. (1970) Haemodynamics and emotional stress. In: Psychosomatics in Essential Hypertension (Ed. by M. Koster, H. Musaph \& P. Visser), p. 13. S. Kargar, Basel. Brown, M., Bresnehan, T.J., Chalke, C.R., Peters, P., Poser, E.G. \& Tougas, R.V. (1956) Personality factors in peptic ulcer. Psychosomatic Medicine, 12, 1.

BRUCE, L.C. \& AleXander, H. DE M. (1900) Physical changes during melancholia. Journal of Mental Science, 46, 725.

BRUNJES, S. (1964) Catecholamine metabolism in essential hypertension. New England Journal of Medicine, 271, 120.

CANNON, W.B. (1932) In: The Wisdom of the Body. Norton, New York.

Carlson, L.A., Levi, L. \& Orö, L. (1968) Plasma lipids and urinary excretion of catecholamines in man during experimentally induced emotional stress, and their modification by nicotinic acid. Journal of Clinical Investigation, 47, 1795.

Chapman, W.P., Livingston, R.B., Livingston, K.E. \& Sweet, W.H. (1950) Possible cortical areas involved in arterial hypertension. Research Publications, Association for Research in Nervous and Mental Disease, 29, 775.

Charvat, J., Dell, P. \& Folkow, B. (1964) Mental factors and cardiovascular diseases. Cardiologia, 44, 124.

Christenson, W.N. \& Hinkle, L.E. (1960) Differences in amount of illness and in signs believed prognostic of atherosclerosis and hypertension in two groups of young men. Paper read on 30 April, 1960. Meeting of the American Federation of Clinical Research.

Cochrane, R. (1969) Neuroticism and the discovery of high blood pressure. Journal of Psychosomatic Research, 13, 21.

CRuz-CoKe, R. (1960) Environmental influences and arterial blood pressure. Lancet, ii, 885 .

Davies, M. (1970) Blood pressure and personality. Journal of Psychosomatic Research, 14, 89.

DiCARA, L.V. \& MiLler, N.E. (1968) Instrumental learning of systolic blood pressure responses by curarized rats: dissociation of cardiac and vascular changes. Psychosomatic Medicine, 30, 489.
Doyle, A.E. \& Fraser, J.R.E. (1961) Essential hypertension and inheritance of vascular reactivity. Lancet, ii, 509.

EYSENCK, H.J. \& EYSENCK, S.B.J. (1964) Manual of the Eysenck Personality Inventory. University of London Press, London.

FarRis, E.J., Yeakel, D.H. \& Medoff, H.W. (1945) Development of hypertension in emotional gray Norway rats after air blasting. American Journal of Physiology, 144, 331.

FishbeIN, G.M. (1963) Perceptual modes and asthmatic symptoms: an application of Witkins hypothesis. Journal of Consulting Psychology, 27, 54.

Folkow, B. \& Rubinstein, E.H. (1966) Cardiovascular effects of acute and chronic stimulations of the hypothalamic defense area in the rat. Acta physiologica Scandinavica, 68, 48.

Glock, C.Y. \& LENNARD, H.L. (1957) Studies in hypertension. V. Psychologic factors in hypertension: an interpretive review. Journal of Chronic Diseases, 5, 175.

GoRDON, B. (1953) An experimental study of dependenceindependence in a social and laboratory setting. Unpublished doctoral dissertation, University of South California (1953).

GraHAM, J.D.P. (1945) High blood pressure after battle. Lancet, i, 239.

Gressel, G.C., Shobe, F.S., Saslow, C., Dubois, P.H. \& SHROEDER, H.A. (1949) Personality factors in arterial hypertension. Journal of the American Medical Association, 140, 265.

Groen, J. (1951) Quoted by Wolf, S. \& WolfF, H.G. A summary of experimental evidence relating life stress to the pathogenesis of essential hypertension in man. In: Hypertension (Ed. by E. T. Bell), p. 327. University of Minnesota Press, Minneapolis.

Groen, J., VAN der Valk, J. \& BastiaAns, J. (1957) A case of malignant hypertension, treated with prefrontal leucotomy and psychotherapy and follow-up for over 8 years. Journal of Psychosomatic Research, 2, 120.

Grollman, A. \& Grollman, E.F. (1962) The teratogenic induction of hypertension. Journal of Clinical Investigation, 41, 710 .

HALL, S.B. (1927) Blood pressure in psychoneurosis. Lancet, ii, 540 .

Hambling, J. (1952) Psychosomatic aspects of arterial hypertension. British Journal of Medical Psychology, 25, 39.

Harris, R.E., Sokolow, M., Carpenter, L.G., Freedman, M. \& HuNT, S.P. (1953) Response to psychologic stress in persons who are potentially hypertensive. Circulation, 7, 874 .

HeINe, B.E. (1970) Psychogenesis of hypertension. Proceedings of the Royal Society of Medicine, 63, 35.

Heine, B.E., Sainsbury, P. \& Chynoweth, R. (1969) Hypertension and emotional disturbance. Journal of Psychiatric Research, 107, 119.

Henry, J.P., Meehan, J.P. \& Stephens, P.M. (1967) The use of psychosocial stimuli to induce prolonged systolic hypertension in mice. Psychosomatic Medicine, 29, 408.

HinkLe, L.E. Jr \& WolfF, H.G. (1961) The role of emotional and environmental factors in essential hypertension. In: Proceedings of the Symposium on Pathogenesis of Essential Hypertension (Ed. by J. H. Cort, V. Fencl, Z. Hejl, \& J. Jirka), p. 129. State Medical Publishing House, Prague.

LACEY, J.I. \& LACEY, B.C. (1962) The law of initial values in the longitudinal study of autonomic constitution. Annals of the New York Academy of Sciences, 98, 1257.

LADER, M. \& Wing, L. (1969) Physiological measures in agitated and retarded depressed patients. Journal of Psychiatric Research, 7, 89.

LenNard, H L. \& Glock, C.Y. (1957) Studies in hypertension: differences in the distribution of hypertension in Negroes and whites. An appraisal. Journal of Chronic Diseases, 5, 186. 
Linton, H. \& Graham, E. (1959) Personality Correlates of Persuasibility in Personality and Persuasibility (Ed. by I. L. Janes et al.). Yale University Press, New Haven.

LOCKET, S. (1955) Oral preparations of rauwalfia serpentina in treatment of essential hypertension. British Medical Journal, 1, 809.

Magoun, H.W. (1963) The Waking Brain, 2nd edn. Thomas, Springfield.

Malmo, R.B., Shagass, C. \& Heslam, R.M. (1951) Blood pressure response to repeated brief stress in psychoneurosis: a study of adaptation. Canadian Journal of Psychology, 5, 167.

MARTIN, I. (1960) In: Handbook of Abnormal Psychology (Ed. by H. J. Eysenck), p. 829. Pitman, London.

Medalie, J.H., KaHN, H.A., Neufeld, H.N., Riss, E., GoldBOURT, U. \& ORON, D. (1970) Association between blood pressure and peptic ulcer incidence. Lancet, ii, 1225.

Miall, W.E. \& Oldham, P.D. (1958) Factors influencing artierial blood pressure in the general population. Clinical Science, 17, 409.

MiaSnikov, A.L. (1961) The significance of disturbances of higher nervous activity in the pathogenesis of hypertensive disease. In: Proceedings of the Symposium on Pathogenesis of Essential Hypertension (Ed. by J. H. Cort, V. Fencl, Z. Hejl \& J. Jirka), p. 153. State Medical Publishing House, Prague.

Miller, M.L. (1939) Blood pressure findings in relation to inhibited aggression in psychotics. Psychosomatic Medicine, 1, 162.

Miller, N.E. (1969) Learning of visceral and glandular responses. Science, 163, 434.

MorRISON, S.L. \& MorRIs, J.N. (1959) Epidemiological observations on high blood pressure without evident cause. Lancet, ii, 864.

Moses, L., Daniels, G.E. \& Nickerson, J.L. (1956) Psychogenic factors in essential hypertension. Psychosomatic Medicine, 18, 473.

Nestel, P.J. (1969) Blood-pressure and catecholamine excretion after mental stress in labile hypertension. Lancet, i, 692.

NewnhaM, C.T. (1952) An analysis of the blood pressure readings of men over 60 years of age examined on the British Railways (Western Region). The Third Congress Union International Medical Chemin de Fer, 27.

OstFeld, A.M. \& Lebovits, B.Z. (1959) Personality factors and pressor mechanisms in renal and essential hypertension. Archives of Internal Medicine, 104, 43.

Ostfel1), A.M. \& SheKelle, R.B. (1967) Psychological variables and blood pressure. In: The Epidemiology of Hypertension (Ed. by J. Stamler, R. Stamler, \& T. N. Pullman), p. 321. Grune and Stratton, New York.

PADDLE, K.C.L. (1928) A review of blood pressure in the insane. Journal of Mental Science, 74, 733.

PARKIN, G.C. (1927) Some observations on the study of the blood pressure in the insane. Journal of Mental Science, 73, 240.

Pickering, G.W. (1968) In: High Blood Pressure, 2nd edn, p. 36. Churchill, London.

Reiser, M.F., Brust, A.A., Shapiro, A.P., Baker, H.M., RANSChOFF, W. \& FerRIs, E.B. (1950) Life situations, emotions and the course of patients with arterial hypertension. Research Publications, Association for Research in Nervous and Mental Disease, 29, 870.

RobINSON, J.O. (1962) A study of neuroticism and casual arterial blood pressure. British Journal of Clinical Psycho$\log y, 2,56$.

Robinson, J.O. (1969) Symptoms and the discovery of high blood pressure. Journal of Psychosomatic Research, 13, 157.
Ruskin, A., BEARD, O.W. \& Schaffer, R.L. (1948) Blas̃ hypertension: Elevated arterial pressure in victims of the Texas City disaster. American Journal of Medicine, 4, $228 \mathrm{D}$

Sainsbury, P. (1960) Psychosomatic disorders and neurosic in out-patients attending a general hospital. Journal of Psychosomatic Research, 4, 26.

Saslow, G., Gressel, G.C., Shobe, F.O., Dubois, P.H. SCHROEDER, H.A. (1950) The possible etiological relevance of personality factors in arterial hypertension. Researct Publications, Association for Research in Nervous and Mental Disease, 29, 881.

SaUL, L.J. (1939) Hostility in cases of essential hypertension Psychosomatic Medicine, 1, 153.

SCHACHTER, H. (1957) Pain, fear and anger in hypertensives and normotensives: a psycho-physiological study. Psycho somatic Medicine, 19, 17.

Scoтch, N.A. (1963) Sociocultural factors in the epidemiolog of Zulu hypertension. American Journal of Public Heali and the Nation's Health, 53, (8), 1205.

SCotch, N.A. \& Geiger, H.J. (1963) The epidemiology of essential hypertension. II. Psychologic and socioculturäh factors in etiology. 16, 1183.

Shapiro, A.P. \& Horn, P.W. (1955) Blood pressure, plasmęr pepsinogen and behaviour in cats subjected to experimentat production of anxiety. Journal of Nervous and Mentab Disease, 122, 222.

Shapiro, D., Tursky, B. \& Schwartz, G.E. (1970) Differentiation of heart rate and systolic blood pressure in me by operant conditioning. Psychosomatic Medicine, 32, $41 \%$

Silverstone, S. \& Kissin, B. (1968) Field dependence essential hypertension and peptic ulcer. Journal of Psychoo somatic Research, 12, 157.

SimONSEN, E. \& BROZEK, J. (1959) Review: Russian reseąch on arterial hypertension. Annals of Internal Medicine, $\bar{\exists}$ 129.

Smirk, F.H. (1957) In: High Arterial Pressure, p. 223룽 Blackwell Scientific Publications, Oxford.

Sokolow, M., Kalis, B.L., Harris, R.E. \& BenNetT, L.Fి (1961) Personality and predisposition to essential hyper tension. In: The Pathogenesis of Essential Hypertensio (Ed. by J. H. Cort, V. Fencl, Z. Hejl \& J Jirka) p. 143. State Medical Publishing House, Prague.

Stamler, J., KJelsberg, M., Hall, Y. \& Scotch, N. (1960 Epidemiologic studies on cardiovascular-renal diseases. I-III. Journal of Chronic Diseases, 12, 440.

Thоmas, C.B. (1967) The psychological dimensions of hyper. tension. In: The Epidemiology of Hypertension (Ed. b J. Stamler, R. Stamler \& T. N. Pullman). Grune an Stratton, New York.

WATERS, W.E. (1971) Headache and blood pressure in the community. British Medical Journal, 1, 142.

Weiss, E., English, O.S., Fischer, H.K., KLeinbart, M. \& ZATUCHIN, J. (1952) The emotional problems of hig blood pressure. Annals of Internal Medicine, 37, 677. WolfF, H.H. (1953) In: Stress and Disease. Thomas, Spring N
field.

Wolf, S., Pfeiffer, J.B., Ripley, H.S., Winter, O.S. \& N WolfF, H.G. (1948) Hypertension as a reaction pattern t£ stress: summary of experimental data on variations ifw blood pressure and renal flow. Annals of Internal Medicine 29, 1056.

Wolf, S. \& WolfF, H.G. (1951) A summary of experimenta! evidence relating life stress to the pathogenesis of essentiad hypertension in men. In: Hypertension (Ed. by E. T. Bell): University of Minnesota Press, Minneapolis. 